\title{
Défice de Fator H: Um Caso com Apresentação Atípica
}

\section{H Factor Deficiency: A Case with an Atypical Presentation}

Ana Paula ROCHA ${ }^{1}$, Madalena BORGES ${ }^{1}$, Conceição NEVES ${ }^{1}$, João Farela NEVES ${ }^{1,2}$ Acta Med Port 2019 Feb;32(2):158-161 - https://doi.org/10.20344/amp.10301

RESUMO

Apresenta-se um caso clínico de um rapaz de 18 meses com défice de fator H com apresentação clínica atípica - otite média aguda recorrente e história familiar da linhagem materna com doença autoimune (vitiligo, tiroidite e púrpura trombocitopénica imune). Analiticamente apresentava $\mathrm{C} 3$ e AH50 diminuídos, assim como properdina e fator $\mathrm{H}$ baixos. O fator I era normal. O estudo molecular do gene $\mathrm{CFH}$ confirmou o diagnóstico de défice de fator $\mathrm{H}$. Esta criança não teve nenhuma das manifestações típicas, nomeadamente doença invasiva por Neisseria meningitidis ou doença renal (glomerulonefrite e síndrome hemolítica urémica atípica). A história familiar de autoimunidade e a correta interpretação dos achados laboratoriais foram fundamentais para o diagnóstico.

Palavras-chave: Criança; Fator H do Complemento; Otite Média; Síndromes de Imunodeficiência

\section{ABSTRACT}

We report a case of an 18-month-old boy with $\mathrm{H}$ factor deficiency with atypical presentation: recurrent acute otitis media and several maternal family members with autoimmune disorders (vitiligo, thyroiditis and immune trombocytopenia). Blood tests revealed low $\mathrm{C} 3$ and $\mathrm{AH} 50$, as well as low properdin and $\mathrm{H}$ factor. I factor was normal. $\mathrm{CFH}$ gene molecular test confirmed the $\mathrm{H}$ factor deficiency diagnosis. This child had none of the typical manifestations of this disorder, namely Neisseria meningitidis infection or renal disease (glomerulonephritis and atypical haemolytic uremic syndrome). Autoimmune family history and correct interpretation of blood tests' results were crucial for this diagnosis.

Keywords: Child; Complement Factor H; Immunologic Deficiency Syndromes; Otitis Media

\section{INTRODUÇÃO}

A otite média aguda (OMA) recorrente é muito frequente em idade pediátrica, por questões anatómicas e exposição repetida a agentes infeciosos. Isoladamente, não costuma associar-se a imunodeficiência primária (IDP), ${ }^{1}$ contudo, perante sinais de alarme e história familiar relevante, é mandatória a sua exclusão. ${ }^{1}$

As IDP são doenças monogénicas que podem afetar qualquer componente do sistema imunitário, na sua maioria raras, com uma prevalência de 1,9-5,6:100 $0000^{2,3}$ As deficiências da via do complemento (VC), um dos tipos de IDP, não se apresentam habitualmente sob a forma de OMA recorrente, ${ }^{1}$ mas sim com infeções disseminadas a Neisseria, doenças causadas por imunocomplexos ${ }^{5}$ e, mais raramente, com manifestações autoimunes, angioedema hereditário ou síndrome hemolítica urémica atípica (SHUa). ${ }^{6}$

No défice de fator $\mathrm{H}(\mathrm{DFH})$, uma proteína reguladora da via alternativa (VA) do complemento, os doentes apresentam habitualmente doença renal, mas estão descritos casos de doentes com lúpus, meningococcémia e infeções de repetição. .,6-8 $^{-1}$

Apresenta-se um caso clínico de uma criança com OMA recorrente e história familiar de autoimunidade, na qual se diagnosticou um DFH.

\section{CASO CLÍNICO}

Criança de 18 meses, género masculino, filha de pais não consanguíneos, com antecedentes pessoais de OMA recorrente (2 episódios/mês desde os 9 meses, com colocação de tubos de ventilação transtimpânicos aos 12 meses), que foi referenciada à consulta de IDP de um hospital terciário.

Dos antecedentes familiares destacava-se a presença de patologia autoimune em múltiplos familiares da linhagem materna (Fig.1).

O exame objetivo era normal. Realizou investigação analítica (Tabela 1), destacando-se: imunoglobulinas (G, $A, M$ e E) normais e serologias vacinais de difteria e tétano protetoras. A eletroforese de proteínas apresentava diminuição da fração $B 2(0,9 \mathrm{~g} / \mathrm{L} / 1,3 \%)$ e o estudo do complemento revelou $\mathrm{CH} 100$ normal com $\mathrm{C} 4$ normal e $\mathrm{C} 3$ baixo (Tabela 1). Por suspeita de consumo de C3 secundário a alteração da regulação da VA, prosseguiu-se investigação que revelou AH50 baixo com properdina e fator $\mathrm{H}$ baixos, resultados confirmados em segunda determinação (Tabela 1). Fez estudo de autoimunidade com anticorpos antinucleares positivos (título 1/80) com padrão mosqueado.

O estudo genético por sequenciação de nova geração de painel de genes do complemento ( $\mathrm{CFH}, \mathrm{CFI}$, $C D 46)$ revelou uma heterozigotia composta no gene $\mathrm{CFH}$ : p.Cys630Ser (não descrita previamente mas cuja análise bioinformática prediz ser patogénica) e p.Trp920Arg previamente descrita, ${ }^{9}$ confirmando-se a hipótese diagnóstica de DFH.

O doente fez vacinação anti-pneumocócica (vacina

\footnotetext{
1. Unidade de Imunodeficiências Primárias. Serviço de Pediatria. Hospital Dona Estefânia. Centro Hospitalar Lisboa Central. Lisboa. Portugal.

2. Chronic Diseases Research Center. NOVA Medical School. Lisboa. Portugal.

$\triangle$ Autor correspondente: Ana Paula Rocha. paulasacrocha@gmail.com

Recebido: 27 de janeiro de 2018 - Aceite: 13 de abril de 2018 | Copyright @ Ordem dos Médicos 2019
} 
conjugada 13-valente seguida da polissacarídica 23-valente) e anti-meningocócica (conjugada tetravalente e de 4 componentes contra o meningococo B). Foi explicada a necessidade de vigilância de doença renal pelo risco de

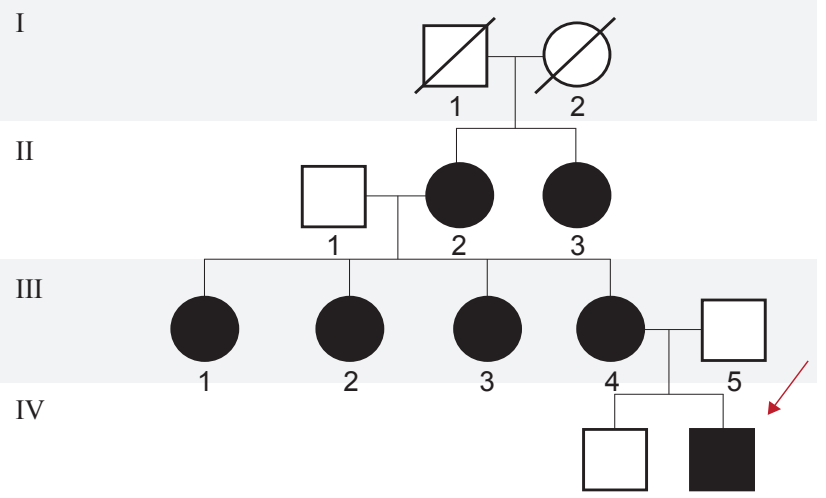

Figura 1 - Heredograma demonstrando diversos familiares maternos com patologia autoimune. Elemento II2: púrpura trombocitopénica imune (PTI) e tiroidite autoimune; elemento II3: vitiligo e tiroidite autoimune; elementos III1-III4: vitiligo.
SHUa e proposto estudo genético à restante família, que recusou.

Atualmente com oito anos, mantém seguimento em consulta de IDP não havendo registo de episódios de otites nem intercorrência infeciosa major ou renal.

\section{DISCUSSÃO}

A avaliação laboratorial de uma criança com suspeita de défice imunitário inclui, entre outros, a análise do complemento.

Classicamente, os defeitos dos componentes iniciais da via clássica (C2 e C4) cursam com doenças mediadas por imunocomplexos, os defeitos de C3 com infeções graves e recorrentes a agentes capsulados, e os defeitos do inibidor da $\mathrm{C} 1$ esterase com angioedema hereditário. ${ }^{3,5,6}$ Os defeitos do complexo de ataque à membrana (CAM) (C5-C9) manifestam-se por doença invasiva meningocócica (recorrente ou causada por serogrupos incomuns), e os da regulação da VA têm manifestações semelhantes aos defeitos do CAM, no caso dos défices de properdina e fator $D$, ou apresentam-se com glomerulonefrite membranoproliferativa

Tabela 1 - Estudos analíticos realizados ao longo da investigação etiológica

\begin{tabular}{|c|c|c|c|c|c|}
\hline & 19 meses & 20 meses & $\begin{array}{l}2 \text { anos e } \\
2 \text { meses }\end{array}$ & $\begin{array}{l}7 \text { anos e } \\
1 \text { mês }\end{array}$ & Valores de referência \\
\hline Hemoglobina (g/dL) & 12,1 & & & & \\
\hline Leucócitos (x 10³) & 7200 & & & & \\
\hline Neutrófilos ( $\% / n^{\circ}$ abs) & $27,2 \% / 2000$ & & & & \\
\hline Leucócitos ( $\% / n^{\circ}$ abs) & $55 \% / 3900$ & & & & \\
\hline Eosinófilos ( $\% / n^{\circ}$ abs) & $3,8 \% / 300$ & & & & \\
\hline Monócitos (\% / $n^{\circ}$ abs) & $13,1 \% / 900$ & & & & \\
\hline Plaquetas & 265000 & & & & \\
\hline Eletroforese proteínas & $\begin{array}{l}\text { Diminuição } \\
\text { fração } \beta 2\end{array}$ & & & & \\
\hline $\operatorname{lgG}(g / d L)$ & 11,3 & & & & $5,33-10,7$ \\
\hline $\lg A(g / d L)$ & 0,34 & & & & $0,24-1,20$ \\
\hline $\lg M(g / d L)$ & 0,89 & & & & $0,72-1,6$ \\
\hline IgE (KUI/L) & 6,8 & & & & $0-60$ \\
\hline Serologias vacinais & $\begin{array}{l}\text { Ac anti-difteria } \\
(\operatorname{lgG})>2 \mathrm{UI} / \mathrm{mL} ; \\
\text { ac anti-tétano } \\
\text { (IgG): } 0,36 \mathrm{UI} / \mathrm{mL}\end{array}$ & $\begin{array}{l}\text { Streptococcus } \\
\text { pneumoniae: } \\
\text { ac IgG } 59 \mathrm{mg} / \mathrm{dL} \text {; } \\
\text { ac IgM } 4 \mathrm{mg} / \mathrm{dL}\end{array}$ & & & $\begin{array}{l}\text { Ac anti-difteria }(\operatorname{lgG})>1 \mathrm{UI} / \mathrm{mL} \text {; } \\
\text { ac anti-tétano }(\mathrm{IgG})>1,5 \mathrm{UI} / \mathrm{mL} \text {. } \\
\text { Streptococcus pneumoniae: } \\
\text { ac } \operatorname{lgG} 0,8-261,2 \mathrm{mg} / \mathrm{dL} ; \\
\text { ac IgM 1,2 - } 113,4 \mathrm{mg} / \mathrm{dL}\end{array}$ \\
\hline CH100 (UCH100/mL) & 900 & & 1000 & 446 & $392-1019$ \\
\hline C3 (g/dL) & 0,06 & & 0,07 & 0,12 & $0,9-1,8$ \\
\hline $\mathrm{C} 4(\mathrm{~g} / \mathrm{dL})$ & 0,3 & & 0,39 & & $0,1-0,4$ \\
\hline AH50 (\%) & & 52,5 & 8,9 & 0 & $52-111$ \\
\hline Properdina (mg/dL) & & 2,5 & 1,4 & & $10,0-40,0$ \\
\hline Fator H (mg/dL) & & & 25,6 & 18,9 & $47,47-65,99$ \\
\hline Fator I (mg/dL) & & & $>11,4$ & 2,69 & $2,38-3,19$ \\
\hline MBL* (ng/mL) & & & 1260 & & $103-3308$ \\
\hline ANA $^{* *}$ & & & $\begin{array}{c}\text { Positivo } \\
\text { mosqueado }(1 / 80)\end{array}$ & & \\
\hline
\end{tabular}

$\mathrm{MBL}^{*}$ : Mannose-binding lectin; $\mathrm{ANA}^{* *}$ : anticorpos antinucleares.

Nota: a história familiar de autoimunidade foi conhecida entre a segunda e a terceira consulta. 

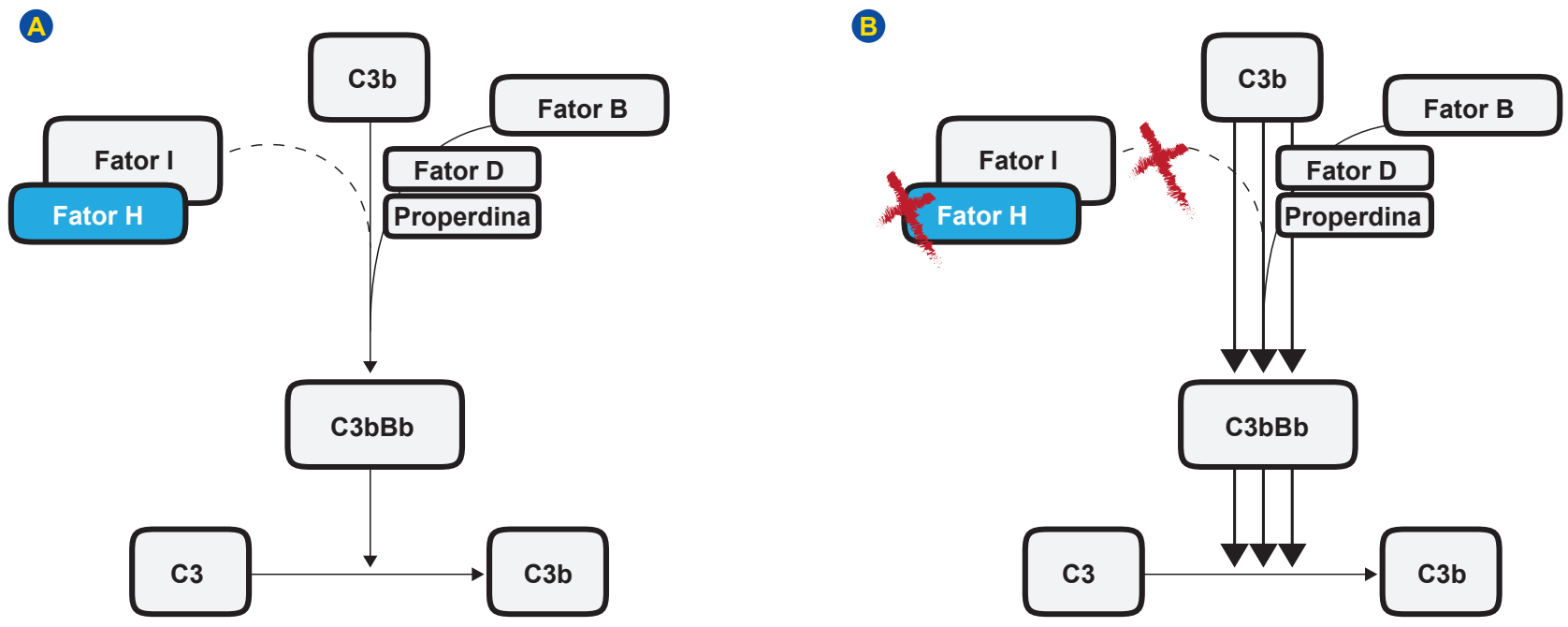

Figura 2 - (A) Esquema ilustrativo da via alternativa e seus fatores reguladores. (B) Esquema ilustrativo do défice de fator $\mathrm{H}$. Setas contínuas: ação ativadora; setas a tracejado: ação inibidora; C3b: C3 convertase; C3bBb: C3 convertase forma ativa.

e SHUa, no caso dos défices de fator I e H..$^{3,5,6,8}$

Apesar de no caso descrito a única clínica presente ser a OMA recorrente, há casos descritos de DFH com OMA, bronquite ou até assintomáticos. ${ }^{4,7}$ Neste caso, a única clínica presente era de OMA recorrente.

$\mathrm{O}$ facto de termos detetado mais do que um componente da VC diminuído orientou o diagnóstico no sentido de um defeito de uma proteína reguladora. ${ }^{6,7}$

Existem múltiplos mecanismos de controlo da VC, sendo os principais inibidores da VA o fator I e o fator $\mathrm{H}$, que atua como cofator do fator I (Fig. 2). ${ }^{10-12} \mathrm{O}$ fator I faz a degradação proteolítica do $\mathrm{C} 3 \mathrm{~b}$ e o fator $\mathrm{H}$ favorece a ação do fator I; a properdina é uma proteína ativadora da VA, através da estabilização da C3 convertase (C3bBb). ${ }^{5}$ Assim, o DFH (tal como de qualquer outra proteína reguladora) leva a uma ativação descontrolada da $\mathrm{VA}, 5,6,11$ culminando no consumo de properdina e da fração C3, justificando as alterações analíticas encontradas no nosso doente..$^{4,6,11}$ Outro indicador do consumo de fatores da VA é a oscilação de valores (properdina e $\mathrm{AH} 50$ ), provavelmente relacionada com o estadio de doença, ${ }^{6}$ nomeadamente intercorrências infeciosas ou outros fatores que possam ativar a VC.

O fator $\mathrm{H}$ tem também função de 'sinalização' das células do hospedeiro, protegendo-as da ação do complemento. ${ }^{6,12}$ Esta ativação da VC é responsável pela deposição renal de fragmentos do complemento e pela lesão celular mediada pelo CAM: os doentes têm elevado risco de glomerulonefrite membranoproliferativa tipo II, SHUa e de degenerescência macular associada à idade; no caso das mutações do gene $\mathrm{CFH}$, o SHUa tem maior risco de doença renal terminal e falência do transplante..$^{6,8,10-12}$

Alguns autores defendem que a suscetibilidade a infeções meningocócicas dos doentes com DFH é secundária ao défice de $\mathrm{C} 3$ ou de fatores da via terminal do complemento..$^{5,7}$ Contudo, pequenas percentagens deste fator poderão ser suficientes para que este risco seja muito inferior ao do défice congénito. ${ }^{11}$
O conhecimento destes factos salienta a importância do reconhecimento dos sinais de alerta para IDP, mesmo cursando com intercorrências infeciosas minor, particularmente se há antecedentes familiares de autoimunidade, como aconteceu neste caso.

Por último, destaca-se a diminuição da fração em que migram as proteínas do complemento na eletroforese de proteínas, podendo o diagnóstico destes doentes ser feito acidentalmente com base nestas alterações. ${ }^{13}$

O diagnóstico precoce permitiu instituir medidas preventivas adequadas antes do início de manifestações mais graves, renais ou de doença autoimune. A vigilância oftalmológica (pelo risco de degenerescência macular associada à idade) e nefrológica (pelo risco de SHUa) são também fundamentais.

Finalmente, a descrição deste doente permitiu expandir o conhecimento sobre os DFH e adicionar a variante p.Cys630Ser às já conhecidas como causadoras de doença.

\section{OBSERVAÇÕES}

O caso foi apresentado sob a forma de comunicação oral no Congresso Multiprofissional do Hospital Dona Estefânia, em Lisboa, a 28 de setembro de 2017.

\section{PROTECÇÃO DE PESSOAS E ANIMAIS}

Os autores declaram que os procedimentos seguidos estavam de acordo com os regulamentos estabelecidos pelos responsáveis da Comissão de Investigação Clínica e Ética e de acordo com a Declaração de Helsínquia da Associação Médica Mundial.

\section{CONFIDENCIALIDADE DOS DADOS}

Os autores declaram ter seguido os protocolos do seu centro de trabalho acerca da publicação de dados.

\section{CONSENTIMENTO DO DOENTE}

Obtido. 


\section{CONFLITOS DE INTERESSE}

Os autores declaram não ter conflitos de interesses relacionados com o presente trabalho.

\section{REFERÊNCIAS}

1. Urschel S. Otitis media in children with congenital immunodeficiencies. Curr Allergy Asthma Rep. 2010;10:425-33.

2. Bousfiha AA, Jeddane L, Ailal F, Benhsaien I, Mahlaoui N, Casanova $\mathrm{JL}$, et al. Primary immunodeficiency diseases worldwide: more common than generally thought. J Clin Immunol. 2013; 33:1-7.

3. Notarangelo LD. Primary immunodeficiencies. J Allergy Clin Immunol. 2010;125:182-94.

4. Reis ES, Falcão DA, Isaac L. Clinical aspects and molecular basis of primary deficiencies of complement component $\mathrm{C} 3$ and its regulatory proteins factor I and factor H. Scand J Immunol. 2006;63:155-68.

5. Wen L, Atkinson JP, Giclas PC. Clinical and laboratory evaluation of complement deficiency. J Allergy Clin Immunol Pract. 2004;113:585-93.

6. Frazer-Abel A, Sepiashvili L, Mbughuni MM, Willrich MA. Overview of laboratory testing and clinical presentation of complement deficiency and dysregulation. Adv Clin Chem. 2016;77:1-58.

7. Fijen CA, Kuijper EJ, Bulte MT, Van de Heuvel MM, Holdrinet AC, Sim $\mathrm{RB}$, et al. Heterozygous and homozygous factor $\mathrm{H}$ deficiency states in a Dutch family. Clin Exp Immunol. 1996;105:511-16.

8. Dragon-Durey MA, Frémeaux-Bacchi V, Loirat C, Blouin J, Niaudet P,

\section{FONTES DE FINANCIAMENTO}

Sem fontes externas de financiamento para a realização deste artigo.

Deschenes G, et al. Heterozygous and homozygous factor h deficiencies associated with hemolytic uremic syndrome or membranoproliferative glomerulonephritis: report and genetic analysis of 16 cases. J Am Soc Nephrol. 2004;15:787-95.

9. Noris M, Caprioli J, Bresin E, Mossali C, Pianetti G, Gamba S, et al. Clin J Am Soc Nephrol. 2010:1844-59.

10. Boona CJ, van de Karb NC, Kleveringa BJ, Keunena JE, Cremersc FP, Klaverd CC, et al. The spectrum of phenotypes caused by variants in the CFH gene. Mol Immunol. 2009;46:1573-94.

11. Ram S, Lewis LA, Rice PA. Infections of people with complement deficiencies and patients who have undergone splenectomy. Clin Microbiol Rev. 2010; 23:740-80.

12. Ferreira VP, Pangburn MK, Cortés C. Complement control protein factor $\mathrm{H}$ : the good, the bad and the inadequate. Mol Immunol. 2010;47:218797.

13. Dejoie T, Audrain M, Bach-Ngohou K, Denis M, Legoue-Morillon $S$, Thomas $\mathrm{C}$, et al. Un exceptionnel déficit héréditaire en fraction $\mathrm{C} 3 \mathrm{du}$ complément dépisté par électrophorèse des protéines sériques. Ann Biol Clin. 2009;67:715-9. 